\title{
Cultura informacional: uma análise léxico-morfológica
}

\author{
Alexandre Robson Martines ${ }^{I}$ \\ http://orcid.org/0000-0002-4524-0978 \\ Luana Maia Woida ${ }^{I I}$ \\ http://orcid.org/0000-0003-3621-9154
}

Carlos Cândido Almeida ${ }^{I I I}$

http://orcid.org/0000-0002-8552-1029

I Universidade Estadual Paulista Júlio de Mesquita Filho, SP, Brasil.

Mestre em Ciências da Informação.

II Universidade Estadual Paulista Júlio de Mesquita Filho, SP, Brasil.

Pós-doutora em Documentação pela Universidad Carlos III de Madrid (Espanha).

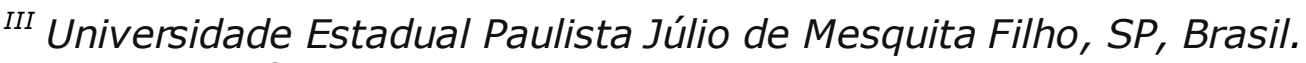

Doutor em Ciência da Informação.

http://dx.doi.org/10.1590/1981-5344/4040

A Cultura Informacional se estabeleceu no cenário da Ciência da Informação e seu objetivo é discutir os valores culturais voltados à informação como indicadores determinantes para retratar uma realidade informacional. A intenção é compreender a Cultura Informacional para identificar as necessidades de informação, organizar a informação e o conhecimento para definir estratégias de controle, intervenção, sistematização e disseminação do conhecimento desenvolvido e proposto nos contextos e domínios em que são aplicados. Somado a isso, há um fator importante para se debater sobre Cultura 
Informacional: a terminologia adequada para nomear a área. Após a criação do termo, o conceito passou a ser explorado em vários debates, dentro e fora da Ciência da Informação, no entanto, por não haver uma definição terminológica, vários termos foram aplicados para resgatar o conceito, fator que proporcionou dificuldades para recuperar trabalhos de pesquisa. Diante disso, a proposta deste trabalho é fazer uma análise linguísticoterminológica a fim de identificar na linguística teorias que contribuem para a adequação do melhor termo ao cenário científico-social e às constituições semânticas na estruturação da expressão, bem como sua representação discursiva. Para tanto, realizou-se uma pesquisa qualitativa, exploratória e descritiva sobre o posicionamento dos especialistas na área, assim como nos fundamentos da Morfologia para analisar a constituição terminológica. Ademais, compreende-se ser necessário resgatar definições sobre as teorias envolvidas, se não pôr fim à discussão acerca do termo, ao menos, fornecer ferramentas estruturais para alinhar às expectativas produzidas no cenário sobre a função que ocupa na Ciência da Informação.

Palavras-chave: Cultura Informacional. Análise LéxicoMorfológica. Terminologia. Análise Metalinguística. Tradução Terminológica. Representação Discursiva.

\section{Information culture: a lexical- morphological analysis}

The Informational Culture was established in the Information Science scenario and its objective is to discuss the cultural values related to information as determining indicators to portray an informational reality. The intent is to understand the informational culture to identify the needs of information, organize the information and the knowledge to set control strategies, 
intervention, systematization and dissemination of knowledge developed and proposed in contexts and domains in which they are applied. However, there is an important factor to debate about informational culture: the terminology for naming the area. After the creation of the term, the concept began to be exploited in various debates, both within and outside the Information Science, however, because there is a terminological definition, various terms were applied to rescue the concept, factor that resulted in difficulties to rescue research papers. Given this, the purpose of this work is to conduct a linguistic analysis to identify terminology in Linguistics theories that contribute to the adequacy of the best term to the scientific-social scenario and to the semantic constitutions in the structuring of expression, as well as its discursive representation. To this end, a qualitative, exploratory and descriptive research was carried out on the positioning of specialists in the area, as well as on the fundamentals of Morphology to analyze the terminological constitution. In addition, it is understood that it is necessary to recover definitions about the theories involved, if it does not end the discussion about the term, at least, provide structural tools to align with the expectations produced in the scenario about the role it occupies in Information Science.

Keywords: Informational Culture. Lexical-Morphological Analysis. Terminology. Metalinguistic Analysis. Terminology Translation. Discursive Representation.

Recebido em 28.06.2019 Aceito em 18.03.2021

\section{Introdução}

A Cultura Informacional se estabelece recentemente nas discussões da Ciência da Informação. O termo surgiu em 1988, quando Ginman discutiu os valores culturais, como as pessoas, as práticas, a tecnologia, a economia, entre outras, voltados à informação como indicadores determinantes para o ambiente informacional, isto é, a cultura informacional como a cultura em que "a transformação dos recursos 
intelectuais é mantida ao lado da transformação de recursos materiais" (GINMAN, 1988 apud CHOO et al., 2008, p. 793, tradução nossa).

Além disso, essa dinâmica se efetua sob a estrutura organizacional e documental, pois "os principais recursos para esse tipo de transformação são vários tipos de conhecimento e informações", consequentemente, "o resultado obtido é um produto intelectual processado, necessário para que as atividades materiais funcionem e se desenvolvam positivamente" (GINMAN, 1988 apud CHOO et al., 2008, p. 793, tradução nossa).

Decorrente a isso, Ginman trouxe à luz o tema cultura

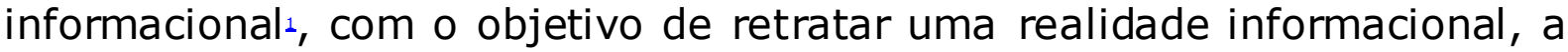
partir da perspectiva de centros executivos, que levam em consideração aspectos sociais e culturais no tratamento da informação e de documentos. Nesse caso, apesar do debate proposto pelo pesquisador ser ainda voltado ao reconhecimento de indicadores culturais para a consolidação do conhecimento e de informações, a intenção era compreender a cultura informacional para identificar as necessidades de organizar a informação e o conhecimento para definir estratégias de controle, intervenção, sistematização e disseminação do conhecimento desenvolvido e proposto nos contextos e domínios em que são aplicados.

Entretanto, quando, no cenário da Ciência da Informação, debate-se sobre a cultura informacional, o foco não está centrado apenas no conceito teórico que evidencia a atuação do tema no campo, ou ainda sobre as práticas, procedimentos, estratégias ou metodologia, como também acerca do limite de suas representações frente a sua atuação no cenário informacional. Além desses fatores e do entendimento de sua contribuição para a Ciência da Informação, mais um fator é importante para se compreender as configurações da cultura informacional: a terminologia.

Após a criação do termo, o conceito passou a ser explorado em vários debates, dentro e fora da Ciência da Informação, a fim de compreender suas proporções e abordagens, no entanto por não haver uma definição terminológica estabilizada, surgiram, marcados nos trabalhos de especialistas da área, vários termos aplicados para resgatar o conceito.

Essa variedade de termos que se alinhavam à concepção em torno da Cultura Informacional proporcionou dificuldades para recuperar trabalhos de pesquisa e as informações sobre o avanço na área, gerando ambiguidades e divergências na interpretação, pois variações terminológicas abrem espaço para entendimentos diferenciados, por conseguinte prejudicando o desenvolvimento e o ajuste à área, já que nem todas as pesquisas são recuperadas adequadamente, ou agrupadas ou relacionadas ao tema. 
Se já não bastasse a pluralidade da terminologia, na intenção de ratificar a ideia e fundamentar sua importância para as áreas envolvidas e as necessidades relacionadas, a tradução para outras línguas também proporcionou uma abertura no leque terminológico.

Nessa linha, entende-se ser importante uma revisão linguística, explorando a Lexicologia e a Lexicografia, assim como seus diálogos com a Morfologia, bem como aplicações da sintaxe e semântica a fim de estabilizar o termo aplicado no cenário da Ciência da Informação, com o intuito de dirimir as discrepâncias na difusão e recuperação das informações e pesquisas atreladas ao contexto da Cultura Informacional.

Diante disso, o objetivo desta pesquisa é uma análise linguísticoterminológica acerca do termo cultural informacional, cultura da informação e cultura de informação a fim de identificar, na linguística, fundamentações que contribuem para a adequação morfológica desses termos aplicados aos aspectos semânticos para nomear o cenário que envolve a Cultura Informacional. Dessa maneira, ajustar a terminologia ao discurso e ao domínio adequado, assim como à comunidade discursiva interessada nesta área de atuação da Ciência da Informação. Para tanto, torna-se importante resgatar definições de vários teóricos que discutiram o tema a fim de evidenciar como se posicionam sobre a problemática terminológica.

Para se debater sobre a aplicação terminológica de cultura informacional, cultura da informação e cultura de informação, propõe-se uma pesquisa de natureza qualitativa, à base de revisão bibliográfica, do tipo exploratória, a fim de analisar as propostas dos estudiosos da área, bem como investigar na linguística fundamentos que constituem o processo de formação de palavras, os fundamentos sintáticos e sua concepção semântica, como elemento terminológico, assim como material linguístico inerente a sua atribuição social.

Outrossim, a pesquisa também se caracteriza por ser descritiva, já que há a apresentação das concepções teóricas acerca do termo, bem como as concepções linguísticas para melhor desempenho semântico frente ao domínio interessado e à comunidade discursiva envolvida. Sendo assim, a coleta de dados ocorrerá através de consultas a artigos, livros e dicionários; a análise das informações tem por finalidade evidenciar as discussões e propostas, como ainda tratar linguisticamente do problema; por fim, a interpretação ocorrerá a partir da triangulação entre o posicionamento dos especialistas do campo, como também, aos olhos da linguística - Lexicologia e Lexicografia -, o termo que melhor responde à necessidade da área.

Portanto, é preciso buscar na Morfologia explicações para o processo de formação da palavra, bem como o impacto semântico na escolha dos sufixos, assim compreender as implicações paradigmáticas, ou seja, a 
relevância da troca lexical. Somado a isso, é importante perceber as relações sintagmáticas - estrutura sintática - e se estas promovem, no campo semântico, relações de sinonímia, homonímia, ou ainda paronomínia com outros termos já aplicados para designar a área.

Acredita-se também ser relevante uma análise da aceitação dos termos pelos especialistas, nos contextos utilizados, assim como 0 posicionamento dos discursos envolvidos para compreender como os termos apontados dialogam com os domínios e contextos e, dessa forma, retratam os aspectos discursivos. Dessa maneira, entende-se ser possível delimitar as considerações acerca do termo e promover reflexões sobre como deva ser a sua representação e qual é o melhor termo para indexar, recuperar e disseminar no cenário da Ciência da Informação.

Espera-se contribuir significativamente com o debate sobre a aplicação do termo, a fim de fortalecer o conceito, já que gradativamente tem se mostrado, ao longo dos anos, ser importante para a Ciência da Informação, tendo em vista que a Cultura Informacional se insere no debate sobre os processos de gestão, disseminação e organização de informação e do conhecimento, porém a divergência do termo escolhido para representar o conceito tem prejudicado o entendimento do assunto, além da recuperação precisa dos trabalhos desenvolvidos, principalmente no que tange a pesquisas bibliométricas, assim comprometendo o desenvolvimento em linhas ampliadas de pesquisas aplicadas sobre o tema na área.

\section{Dos termos e dos conceitos}

As dinâmicas sociais promovem transformações nos diversos contextos e cenários. Efetivamente, as relações atuais não mantiveram as mesmas regras de conduta como as de algumas décadas; as transformações são certas, principalmente diante dos avanços tecnológicos, assim como as relações sociais e culturais. Hegel (1807) denominou esse fenômeno de dialética histórica, já que o tempo presente dialoga com os fenômenos do passado a fim de reajustar e renovar no futuro (HEGEL, 1992). A tecnologia tem exercido grande influência nas linhas comportamentais de seus usuários, assim determinando comportamento e construção de conhecimento.

Assim, surgem novas práticas, novos áreas da ciência e com elas, destacam-se seus conceitos e o aparato terminológico para fundamentar o trabalho. A formulação dos pensamentos se caracteriza pela relação do binômio termo-conceito, esse fenômeno do intelecto está marcado pela transição do complexo da palavra para a formatação histórica, à base de interação social, na constituição do conceito, pois é inerente ao pensamento, à cognição e ao intelecto (VYGOTSKY, 2007). 
Sendo assim, torna-se fundamental a discussão presente neste trabalho referente a essa constituição terminológica no que tange à Cultura Informacional. Tendo em vista que as pesquisas na área têm demonstrado interesse em definir a abrangência do conceito, problemas referentes à tradução e uso histórico - desde quando o conceito ainda não havia se formalizado em área da Ciência da Informação, sendo apenas um aparato de contribuição nas análises e avaliações dos fluxos informacionais -, proporcionaram divergências quanto ao termo, ou seja, essa discussão já demanda um certo tempo.

Importante resgatar a ideia de que "a linguagem constitui a capacidade do homem designar os objetos que o circundam, assim como de comunicar-se com os seus semelhantes", a qual anuncia a importância do conceito para a tradução dos elementos da realidade em pensamentos (DAHLBERG, 1978, p. 101). Sendo assim, o conceito é fundamental para classificar a Cultura Informacional, já que é constituído de seus elementos predicativos. Além disso, é importante destacar a preocupação dos pesquisadores com sua configuração, pois é "formulando enunciados sobre atributos necessários ou possíveis dos objetos que se obtém as características dos respectivos conceitos" (DAHLBERG, 1978, p. 102).

Outrossim, o conceito é um elemento necessário para classificar e é constituído pela sua relação de domínio, além de estabilizar a ciência sob a perspectiva de um paradigma. Ademais, o conceito confere para o domínio estabilidade, representação e definição linguística, processo de abstração e transposição metafísica, além de fundamentações epistemológicas (HJORLAND, 2009, tradução nossa).

Nessa perspectiva, R. Barthes é bem enfático ao dizer que a ciência é estruturada por sua terminologia, fator que evidencia o que o autor denomina de mito, assim como defende que a linguagem constrói o mito (BARTHES, 2006). Diante disso, entende-se que, mesmo sendo uma área recente, ainda em pleno desenvolvimento, Cultura Informacional requer seu espaço como mito linguístico, devido a sua importância como área da ciência, assim como suas propriedades sociais, culturais, políticas, organizacionais, informacionais, pedagógicas e tecnológicas.

Um fator determinante para o fortalecimento da Cultura Informacional nos estudos da Ciência da Informação é a caracterização do fluxo de informação, já que o acesso à informação se tornou, aparentemente, mais fácil devido à contribuição tecnológica e o acesso a documentos, porém ações pedagógicas para promover criticidade na construção do conhecimento ainda não é acessível a todos integrantes de uma comunidade, dificultando as estratégias, as práticas e a inovação organizacional. Diante disso, o cenário empresarial percebeu a importância de se constituir a organização de informações para que houvesse qualidade na produção de conhecimento. 
Destarte, Moraes e Barbosa (2015) justificam o porquê de os pesquisadores se importarem com o tema, pois a Cultura Informacional, ao mesmo tempo, efetiva "a questão informacional e a questão cultural, que se traduzem no papel da informação e do conhecimento e o papel da cultura organizacional na sobrevivência, eficácia e competitividade das organizações" (MORAES; BARBOSA, 2015, p. 131).

Os pesquisadores apontam que ao analisarem que o tema ganhou importância a partir da década de 1980, levantam uma relação de outros teóricos e pesquisadores preocupados com o fenômeno (MORAES; BARBOSA, 2015). Essa análise consiste em apontar o despertar da Cultura Informacional para esse contexto:

Na confluência das questões informacional e cultural situa-se o tema da cultura informacional, que emergiu como subproduto das pesquisas sobre cultura organizacional e sobre os efeitos da informação e do conhecimento frente às novas tecnologias da informação e da comunicação (TIC) nas organizações. (MORAES; BARBOSA, 2015, p. 131-132)

Há, portanto, uma preocupação acerca do tema, devido a sua abrangência, por conseguinte sobre seus efeitos:

A preocupação com esse tema - cultura informacional - surgiu assim de forma difusa e secundária. Assim, a partir da metade da década de 1990, proliferam os estudos que exploram os relacionamentos entre cultura, informação, conhecimento e tecnologia ao desempenho organizacional, assim como estudos relativos à cultura informacio nal propriamente, em diversos campos do conhecimento (MORAES; BARBOSA, 2015, p. 132)

Assim, observa-se a dificuldade inicial para delimitar as fronteiras significativas do tema, até mesmo como ocorre seu surgimento é difuso, além disso os autores também apontam uma outra complicação: o termo. Os autores apontam que uma revisão de literatura mostrou que o termo cultura informacional é usado em distintos campos de conhecimento, aparecendo na maioria das vezes com significações diferentes. (MORAES; BARBOSA, 2015, p. 132)

Após analisar vários teóricos e pesquisadores, entende-se a necessidade de constituir um conceito a fim de evocar o que o tema representa para a área científica específica e correlatas, já que os pesquisadores identificaram que outras áreas dialogam com Ciência da 
Informação a fim de fortalecer os cenários em que o tema é explorado e aplicado.

Sendo assim, Moraes e Barbosa (2015) não definem categoricamente os limites do tema, visto que cultura está "intrinsecamente ligada às transformações humanas, e esta vive em constantes transformações", contudo os autores oferecem "um conceito norteador" a fim de corroborar a efetivação do tema nos meandros científicos sem desfocar seu principal objetivo. (MORAES; BARBOSA, 2015, p. 136).

Ainda sobre as acepções referentes ao tema e ao termo, vale buscar mais análises e considerações para estruturar uma reflexão de sua composição linguística, visto que os diversos contextos em que o termo é aplicado, de fato, constituirá sua significação. A morfologia é um aparato físico; a designação de um nome é um procedimento arbitrário, de ordem da convencionalidade (SAUSSURE, 2006) e nem sempre se caracteriza como orgânico na aplicabilidade e relação. Ademais, o discurso é composto de duas classes: nome e verbo, sendo assim a elocução apenas ocorre quando se estabelece o significado. (ROSA, 2018).

Ademais, depois da revolução científica, ontológica e terminológica do século XIX, as línguas passariam "a ser classificadas segundo a nitidez das fronteiras entre os elementos" (ROSA, 2018, p. 63). Nessa linha, a língua é um sistema (SAUSSURE, 2006), ao qual é designado valores, portanto é fundamental a definição normalizada da área para se fixar na constituição discursiva.

Sobre os aspectos da Cultura Informacional, para Sundqvist e Svärd (2015), definir os limites conceituais da Ciência da Informação não é tarefa das mais fáceis. Assim, os teóricos apontam:

Uma construção teórica usada para abordar o papel das normas, atitudes e o modo como as organizações valorizam a informação é a cultura informacional. A informação é, no entanto, um conceito polissêmico e fluido, e sua relação com o conceito de registros não é indiscutível. A cultura também é um conceito indescritivel. Para estar operacional, um conceito deve ser definido para chegar a uma compreensão definitiva do que constitui. (SUNDQVIST; SVÄRD, 2015, p. 9, tradução nossa).

Os teóricos também analisaram a evolução do conceito e suas motivações. Depreende-se que o universo empresarial, por conseguinte o organizacional também aderiu às possibilidades e potencialidade da 
Cultural Informacional, dessa forma, como evidências de suas análises, destacam:

O conceito foi então adotado e apropriado por pesquisadores da ciência da informação, com várias definições mais ou menos explícitas. Um pioneiro nesse campo foi Ginman (1987, 1988), que abordou o conceito cultura informacional em seus estudos sobre como a informação e seu manuseio afetavam o desempenho dos negócios, sem, no entanto, explicitamente definir o conceito. Em seu ponto de vista, a cultura informacional era o cenário em que "a transformação dos recursos intelectuais é mantida ao lado da transformação de recursos materiais. Os recursos primários para esse tipo de transformação são tipos variados de conhecimento e informação. A saída alcançada é um produto intelectual processado que é necessário para que as atividades materiais funcionem e se desenvolvam positivamente" (GINMAN, 1988, p. 93 apud SUNDQVIST; SVÄRD, 2015, p. 10, tradução nossa).

Nessa perspectiva, os teóricos entendem que a evolução do termo ocorreu devido à importância que o tema acabou promovendo nos estudos da Ciência da Informação:

O interesse pela cultura informacional pode ser considerado como uma compensação da virada contextual na ciência da informação. Muitas das primeiras pesquisas sobre informação, sua função e uso consideraram as percepções cognitivas dos indivíduos e trataram sua interação com informação e os sistemas de informação como fenômenos isolados. No entanto, pelo menos desde os aspectos contextuais e sociais da informação da década de 1990, seu manuseio e uso têm ganhado atenção. (VAKKARI,1997 apud SUNDQVIST; SVÄRD, 2015, p. 13, tradução nossa).

Ademais, diante das reflexões e contrastes de definições colhidas, Sundqvist e Svärd (2015) chegam a uma síntese em relação à Cultura Informacional: "Aspectos culturais em informação e em gestão da informação são reconhecidos como uma área de pesquisa, no entanto a cultura informacional como um conceito e um fenômeno talvez não seja um problema generalizado." (SUNDQVIST; SVÄRD, 2015, p. 14, tradução nossa).

Ainda sobre a configuração do termo e conceito, Maury e Serres (2010), argumentam a favor sobre a definição de um conceito: 
Ao combinar os dois termos, cultura e informação, o conceito de cultura informacional joga com a polissemia desses termos, o que pode explicar em parte porque a definição do conceito é objeto de muito debate, tanto em nível nacional quanto internacional.

Se o surgimento do conceito é relativamente recente (1980 para alfabetização informacional em países anglo-saxões, 1995 para cultura da informação na França) [M. Mollard, 1996], isso traduz principalmente uma mudança de abordagem na história da formação à informação. (MAURY; SERRES, 2010, p. 28, tradução nossa).

À busca de definir os limites que perfazem o conceito, os autores defendem que Cultura Informacional pressupõe o desenvolvimento de habilidades relacionadas à alfabetização informacional e interação com todo o seu aparato, assim como competências relacionadas a aprender a aprender, já que pensar em Cultura Informacional é compreender as técnicas relacionadas à gestão da informação no seu mais amplo sentido, mas também entender que o fluxo de informação também é algo social e ideológico:

O conceito de alfabetização informacional é, portanto, um conceito plural, forjado na reunião das ciências da informação e comunicação, ciência da computação e ciências da educação em particular. A definição da American Library Association (ALA), que Ihe deu uma forma de consagração em 1989, é mais operativa que conceitual [ALA, 1989]. Indicar o conhecimento necessário para uma pessoa alfabetizada em informação é o elo entre a aprendizagem e a informação e destaca a importância de "aprender a aprender" na "sociedade da informação e conhecimento." (MAURY; SERRES, 2010, p. 28, tradução nossa).

Quando se pensa a dimensão do conceito, é importante compreender que este transcende sua relação com o termo. Se, por um lado, o termo é fundamental para uma indexação coerente e uma recuperação precisa das informações, assim como é responsável pela materialização dos elementos tácitos que transitam na concepção da entidade evocada na constituição do conceito; por outro, é este que produz as reflexões e valida as relações dialógicas entre contextos, ambientes e domínios. O debate sobre a convenção do termo é 
interessante, mas a compreensão sobre a abrangência e a capacidade de revitalização do conceito é essencial.

Ainda sobre as inquietações acerca do termo, Maury e Serres identificam:

Muitos outros termos são usados, seja como equivalente à alfabetização informacional (competência em informação, competência em alfabetização informacional, cultura da informação, cultura informacional, mediação, alfabetização para a era da informação), ou como uma variação de uma dimensão particular (biblioteca, mídia, midiático, computador, digital, rede, internet, hiper, multimídia ... alfabetização), como um imã de noção determinando todos esses termos (transliteração). Entre essas diversas variações, no entanto, a alfabetização informacional permanece, apesar das suas origens "comerciais", a expressão sobre a qual o acordo é maior nos países anglo-saxões. (MAURY; SERRES, 2010, p. 28, tradução nossa).

Em uma perspectiva, à francesa, muito próxima a que Maury e Serres apresentam, Le Deuff (2008) também discute sobre os diferentes termos que são aplicados para referenciar cultura informacional, assim como a dimensão conceitual que evoca o tema. Primeiramente, entendese ser pragmático analisar as questões sobre o conceito: Le Deuff (2008, p. 3, tradução nossa) apresenta: "A cultura da informação é um conceito pouco evidente para definir como as visões encontradas durante nossa pesquisa diferem ou até divergem. O exame de sua existência em outras línguas que não o francês suscita questões" (2008, p. 3, tradução nossa).

Ademais, o autor apresenta preocupações relacionadas à tradução. Dessa forma, entende-se ser essencial resgatar esse questionamento e analisar, no presente trabalho, através dos constructos morfológicos, quais termos - em uma correlação paradigmática e sintagmática - evocam as implicações conceituais, assim como buscar esclarecer quais termos propõem a relação de redes sêmicas.

R. Jakobson (2011) indica que "o significado de um signo linguístico não é mais que sua tradução por outro signo que lhe pode ser substituído, especialmente um signo no qual ele se ache desenvolvido de modo mais completo" (JAKOBSON, 2011, p. 64).

O linguista ainda destaca a tradução interlingual, em que chama de "tradução propriamente dita que consiste na interpretação dos signos verbais por meio de alguma outra língua" (JAKOBSON, 2011, p. 65), fato este que se complementa com a ratificação de que "não há comumente 
equivalência completa entre unidades de código" (JAKOBSON, 2011, p. 65), evidenciando o problema destacado por Le Deuff.

Le Deuff (2008) também questiona os aspectos relacionados ao termo, indicando as dificuldades para condensar uma acepção. As relações entre as línguas não são tão próximas e as traduções podem proporcionar outras referências significativas. Sobre o termo, o autor aponta:

Queríamos voltar novamente ao espinhoso problema da tradução da alfabetização informacional em francês. A Unesco defende o "controle informacional", mas o crescente sucesso do conceito de "cultura informacional" e seu uso equivalente à alfabetização informacional em um recente simpósio canadense merece, portanto, uma revisão. Apenas, optamos por proceder da maneira inversa, procurando como traduzir "cultura informacional" para outras línguas. (LE DEUFF, 2008, p. 3, tradução nossa)

Traz-se a acepção de mais um especialista sobre o tema, com a finalidade de mensurar as problemáticas sobre o termo, situação que sustenta a existência deste artigo e as implicações conceituais evocadas pelas necessidades de ordem organizacional, entretanto também é importante entender como atende às necessidades sociais, educacionais, tecnológicas e comunicativas.

R. Jakobson (2011) destaca a necessidade de que apenas é possível compreender a palavra se houver um conhecimento não-linguístico do conceito, o que caracteriza "o fato linguístico fundamental para que haja um fato semiótico" (JAKOBSON, 2011, p. 63), ou seja, Cultura Informacional ganha forma diante das aplicações mencionadas por Le Deuff (2008), sendo essas acepções fundamentais para moldar seu entendimento e aplicação, as quais são compreendidas pela interação entre os especialistas da área e da área com os aspectos sociais, históricos e culturais.

Pichs Férnadez e Ponjuán Dante (2014) apresentam ponderações sobre o termo: "Os primeiros conceitos sobre o termo de uma forma mais completa emergem para 1998 e 1999 como um tipo de cultura material e subjetiva criada pelas pessoas de acordo com suas capacidades tecnológicas, informacionais e críticas da informação em si" (PICHS FÉRNADEZ; PONJUÁN DANTE, 2014, p. 35, tradução nossa). Além de discutirem sobre a origem do termo, também promovem reflexão sobre as relações terminológicas aplicadas ao tema:

Em geral, pode-se dizer que a malha de cultura informacional se relaciona com outros conceitos: alfabetização informacional, cultura organizacional, fluxos de informação, tecnologias de informação e 
comunicação, colaboração e aprendizagem organizacional, integração da cultura e cultura de análise pessoal da profissão pelo indivíduo, desenvolvimento de processos de informação em função de um adequado gerenciamento de informações e sistemas e ferramentas de gestão (informação e conhecimento), assim como o desenvolvimento da comunicação na organização em todos os níveis, informação que domina o ambiente e a relação da mesma com o fator inovação. (PICHS FÉRNANDEZ; PONJUÁN DANTE, 2014, p. 35, tradução nossa).

Com respeito à entidade conceitual, Pichs Férnadez e Ponjuán Dante (2014) definem:

A existência de uma cultura informacional específica em um determinado contexto é dada por: A conceituação, complexidade e dinâmica da cultura e seus fenômenos ou padrões cultura is que dão lugar a um sistema de (competências informacionais, crenças, costumes e experiências), as motivações, conflitos, gostos, valores e limites em torno do uso de certas informações e conhecimentos, assim como o papel das tecnologias da informação e comunicação e fluxos de informação de uma gestão adequada da gestão da informação. (PICHS FÉRNANDEZ; PONJUÁN DANTE, 2014, p. 35, tradução nossa).

Sendo assim, entende-se que, se por um lado, as relações semânticas que direcionam para a compreensão de um conceito dialogam na maioria dos contextos aplicados; por outro, o consenso sobre a terminologia aplicada não é tão bem definido.

Embora seja perceptível uma rede argumentativa e semântica que garante que todos os termos indicados façam parte do mesmo universo, ainda há dúvidas se podem ser entendidos como sinônimos, ou apenas termos correspondentes ao tema, porém com lexemas distintos, ou ainda entender qual é o limite do diálogo constituídos por seus diversos predicativos. Além disso, ainda é passível a discussão sobre as variantes da própria Cultura Informacional, isto é, se em suas abordagens de gestão, socioeducacional e tecnológico-comunicacional, tal como organizou Woida (2016) todos os termos correlatos possuem o mesmo significado.

\section{Análise léxico-morfológica}


Como observado, há divergência sobre o termo aplicado no que tange ao tema Cultura Informacional. Diante disso, além de debater sobre as abordagens realizadas por diversos pesquisadores e especialistas da área, entende-se também ser fundamental para refletir sobre a pertinência do termo adequado, uma análise linguística, sob a égide da Etimologia, Lexicografia e Morfologia.

Um dos motivos para essa situação é sua constituição histórica, como também os fatores relacionados à tradução. Sobre as questões históricas, entende-se que o termo é recente, surgiu a meio de uma necessidade de compreender os fenômenos informacionais que se caracterizavam na formação das organizações, já que "o comportamento informacional vincula-se à cultura informacional e prepõe ser necessário gerenciá-lo", assim evidenciar nos contextos organizacionais que "a informação tem valor" (DAVENPORT; PRUSAK, 1998 apud WOIDA, 2016, p. 16).

As transformações nas dinâmicas sociais geraram impacto em todos os setores, por conseguinte, exigindo uma compreensão de que havia um fenômeno inerente à cultura organizacionalz, no entanto intrínseco aos fatores sociais de gestão de conhecimento, como a gestão da informação, a organização da informação, assim como a educação sobre a informação, além de aspectos metalinguísticos sobre aprender a aprender esses fenômenos, portanto a necessidade de uma metodologia capaz de analisar, debater, identificar e ensinar as facetas que envolvem o tema.

Vários especialistas, a fim de justificar a aplicação adequada da terminologia, desenvolveram suas pesquisas à base da complexidade da Cultura Informacional, ou seja, além de debaterem sobre as linhas de sistematização teórica, também discutiram o termo adequado, caracterizando a falta de consenso, ao mesmo tempo preocupação com essa situação terminológica. Sobre as linhas teóricas, Moraes e Barbosa (2015, p. 132), classificaram as pesquisas em cinco linhas de trabalho:

a) desempenho organizacional (GINMAN, 1987; ABELL; WINTERMAN, 1992; BROWN; STARKEY, 1994; GRIMSHAW, 1995; WILSON, 2003; CHOO, 2013), b) ciclo de vida da organização (GINMAN, 1987), c) inteligência competitiva (WIDÉN-WULLF, 2000; WOIDA, 2008), d) gestão da informação e do conhecimento (MARCHAND; KETTINGER e ROLLINS, 2000, 2001; CURRY; MOORE, 2003; OLIVER, 2003, 2004, 2008; WANG, 2006), e) implantação de novas tecnologias (TRAVICA, 2005, 2008; AMORIM; TOMAEL, 2011), bem como outros aspectos organizacionais (CURRY; MOORE, 2003; OLIVER, 2003，2004，2008; TRAVICA，2005，2008; WANG, 2006; WOIDA, 2008).

Devido a isso, resgataram o significado de seus termos: cultura e informação separadamente, para, assim, sintetizar o sintagma com a 
finalidade de expressar a entidade conceitual que traduzisse, então, a ideia de um fenômeno organizacional, mas também entrelaçado ao social, já que nasceu por objetivos empresariais e organizacionais, porém no âmago direto do âmbito social, pois a educação da massa sobre a informação, de um modo ou de outro, interfere no fluxo de informação e sua compreensão precisa e aplicável nas organizações.

Pensar em Cultura Informacional é também pensar em um processo pedagógico, já que a organização da informação não é estática, pelo contrário, é fluida, assim seus usuários precisam compreender seus pressupostos, bem como seus subentendidos, para tanto é preciso o desenvolvimento de habilidades e competências que lhe permitam interagir com os diversos contextos (ZABALA, 1995). Além da capacidade de compreender o que é factual, o usuário necessita ser capaz de compreender o que é tácito.

A troca cultural é força motriz para compartilhar informações e, através da interação, promover o conhecimento. Embora o conceito cultura informacional tem se aproximado de um consenso, se não preciso, todavia capaz de estabelecer diálogo e reconhecimento recíproco, já que a revitalização do léxico é um processo natural e constante. Em se tratando de um léxico com tamanha potencialidade significativa, a revitalização deve acompanhar sua dinamicidade e capacidade de dialogar em diferentes áreas do conhecimento, visto que, se cultura informacional ainda não é termo aplicado em outras áreas do conhecimento, por sua vez, dialoga e resgata diversos conceitos das outras áreas.

Outrossim, caracteriza-se como um conceito amplo, plural, multissignificativo, transdisciplinar, mas não deve ser visto como um conceito difuso, já que especialistas interpretaram seu caminho de aplicação e no domínio da Ciência da Informação estabeleceu a abrangência de seus significados. Conforme C. S. Peirce, o contexto é capaz de determinar o significado, pois o signo linguístico está no lugar da coisa representada (PEIRCE, 2000). Deve-se entender que a coisa representada já possui um aparato significativo, vitalizando uma entidade propulsora de enunciados. Porém, o termo, que já ganha uma forma de reconhecimento mais contínua, ainda sofre por não se estabelecer frente a uma tradição.

De um ponto de vista analítico, o vocábulo [informacional] é a expressão que melhor resgata toda a contextualização significativa, porém apenas a historicidade discursiva poderá confirmar. Ademais, Maury (2010) aponta que de 2007 a 2010 houve resultados apresentados em publicações, por especialistas, sobre o conceito Cultura Informacional em relação ao entendimento da reformulação em educação em informação, impactos nas dimensões sociais e culturais, além dos aspectos técnicos, instrumental, metodológico, como ainda treinamento documental, controle 
de informações ou educação de informação, ou seja, essas abordagens apresentam categorias que o conceito é capaz de estabelecer (MAURY, 2010, p. 127).

Sendo assim, compreende-se que esses temas vinculados às discussões sejam produtos da cultura informacional e promovam com ela uma relação de hiponímia, isto é, cultura informacional se caracteriza por ser o conceito chave, atuando como uma prática funcional de hiperônimo, enquanto os outros conceitos dialogam em um campo semântico específico: domínio da Ciência da Informação, atuando como hipônimos.

A interferência da tradução na concepção do termo é, praticamente, - fator mais determinante para as discussões acerca do melhor termo para representar o conceito. Le Deuff (2008, p. 4, tradução nossa) apresenta um quadro de pesquisa sobre os termos mais recorrentes para recuperar o tema e como se configuram em alguns idiomas. Identificada como originária do Anglo-Saxão - Língua Inglesa -, [cultura informacional], muitas vezes, é resgatada como [cultura da informação] ou ainda como [cultura do uso da informação].

Percebe-se que no Inglês aparece [Information Literacy], além de duas outras expressões em evidência: [culture of information] e [information culture]. Essas duas expressões contribuíram para que a tradução ganhasse, na Língua Francesa, as expressões [culture de l'information] e [culture informationelle], além de também aparecer [maîtrise de l'information]. O conceito ainda aparece na Espanha como [Alfabetización Informacional]. No Brasil, por sua vez, é possível encontrar [Competência em Informação] e [Competência Informacional] (LE DEUFF, 2009, apud WOIDA, 2016, p. 16). Como seus respectivos países possuem interesse na área, as expressões foram emprestadas para outras línguas e se ajustaram conforme as características culturais dos léxicos, sem, no entanto, perder as relações primeiras com as línguas precursoras.

Em português, destacam-se as expressões [cultura da informação] e [cultura informacional]. De modo geral, há uma preferência pela segunda expressão, muito embora os autores que se valem do termo não o definam adequadamente. Maury (2010) aponta que no processo de diferenciação das expressões, tal questionamento é pouco formalizado, bem como o exercício de delimitação dos elementos que torna possível distingui-los é delicado, pois esses elementos estão fortemente entrelaçados nas definições (MAURY, 2010, p. 130).

No entanto, entende-se que a cultura informacional é mais adequada do que cultura da informação, já que esta é vista como uma espécie de meta-cultura, por mais que haja alguns debates na antropologia e ciências sociais de que informação seja inerente à cultura, é preciso entender o termo como um denominador de um fenômeno particular, já que ele é um signo que representa algo, e aplicando o senso 
de economia informacional da semiologia de Saussure (1916) esses termos não existiriam se possuíssem o mesmo conceito. Nos termos do linguista, a langue descarta a possibilidade de mais de um significante para o mesmo significado, portanto, evocam interpretantes diferentes, correlacionando à teoria de C. S. Peirce (2000).

Sendo assim, pensar cultura da informação como meta-cultura é entendê-la como um fenômeno social, caracterizando um tipo específico de cultura que se sustenta pelo fluxo da informação privilegiada para um determinado fim, especificado por uma área de atuação, ou seja, a cultura da informação pode ser compreendida como a informação sobre a informação, assim como a cultura específica que corrobora a potencialização da cultura do conhecimento, transbordando apenas lições metodológicas e documentos orientados para a aquisição de uma postura crítico-analítica, enquanto cultura informacional é definida como abordagem de diferentes teorias disciplinares e epistemologias.

Nessa linha, a Cultura Informacional propõe um conceito específico, o qual "provê a direção para os indivíduos manusearem a informação", essa ação não é fruto de uma ação qualquer, mas sim de algo é estratégico para o comportamento informacional e, assim, justifica a relevância da informação para a organização (WOIDA, 2016. P. 18).

Diante disso, entende-se ser importante promover uma análise linguístico-morfológica para entender quais implicações semânticas os elementos que formam as palavras, ou seja, os morfemas, promovem. Inicialmente é preciso destacar que nas expressões [cultura informacional] ou [cultura da informação], o termo [cultura] exerce o papel de substantivo, portanto toda a carga significativa gira em torno desse conceito.

Em seu artigo, Pichs Fernández e Ponjuán Dante (2014) apresentam a preocupação em definir os conceitos de cultura e de informação para depois analisar os dois termos correlacionados (PICHS FERNÁNDEZ; PONJUÁN DANTE, 2014, p. 34). Nessa linha, entende-se que os termos [informacional] e [da informação] exercem respectivamente as funções de adjetivo e locução adjetiva.

Sendo assim, pode levar ao entendimento, a priori, de se tratar apenas de uma escolha paradigmática, ou seja, a configuração da palavra e de sua escolha, contudo essa associação intuitiva está equivocada, pois trata-se de mais uma artimanha da língua e seus falantes em resumir suas correlações semânticas, tendo em vista que suas relações sintagmáticas, a estrutura da frase e a organização sintática, são capazes de gerar sentidos diferentes.

Para clarear a reflexão, é preciso demonstrar o processo de formação da palavra [informação], já que esta é a base de derivação das duas situações. O vocábulo [informação] pertence a uma família cognata 
cujo morfema primordial, ou seja, o radical, também chamado de semantema - devido às promoções semânticas de sememas e semioses e de lexema - por suas atribuições fonológicas e morfológicas, é [forma], que, por sua vez, significa "o modo sob o qual uma coisa existe ou se manifesta; configuração; feitio; feição exterior" (DUBOIS et al, 1998).

De acordo com o dicionário etimológico Nova Fronteira da Língua Portuguesa (1986, p. 364), o vocábulo surgiu no século XIII, derivado do latim forma. Somente no século $X V$, por influências não precisas do espanhol, ou ainda do galego-português, derivado da estrutura enformaçom, -çam, -çon, aplicados inicialmente no século XIV, que, por sua vez, é derivado do latim informātǐōōnis. Do qual será derivado em 1572 o vocábulo [informar], cujo significado consiste em dar instrução a; ensinar (CUNHA, 1982).

Significados que transitam na concepção de cultura informacional, porém cultura informacional envolve mais predicativos que a ideia de ensinar e, somado a isso, o vocábulo [informar] tendo sua natureza como verbo, dele se derivou, por associação ao latim informāre, o vocábulo [informativo] de natureza adjetiva, cujo significado é que se destina a informar ou a noticiar, ou ainda, publicação periódica em que predomina o caráter informativo; boletim. Portanto, etimologicamente, a locução adjetiva [da informação] é correspondente ao adjetivo [informativo]. Pode-se oferecer exemplos para quantificar o raciocínio: da locução adjetiva [da instrução] tem-se o adjetivo [instrutivo], já o adjetivo [instrucional] promove uma outra significação, com características mais abrangentes (CUNHA, 1982).

Observa-se que na relação de deverbal, a relação imediata são vocábulos cujo sufixo é composto por [-ivo], sufixo nominativo, derivado do latim -īvus, que forma adjetivos oriundos de verbos, como noção de referência, modo de ser, ação (BECHARA, 2006). A entidade conceitual de cultura informacional não se limita, destarte, a essas concepções, todavia a expressão cultura da informação sim (MAURY, 2010, p. 130).

Assim podemos sintetizar, através da morfologia e semântica, que o sintagma [cultura da informação] indica que a informação possui uma cultura, um traço significativo, uma conduta, ou seja, a informação possui elementos particulares de um grupo social, um rol de circunstâncias para se constituir, dependendo, definitivamente, do seu contexto, ou seja, há uma gama de elementos culturais que direcionam a aplicabilidade da informação.

A informação será transmitida conforme a cultura do grupo social que está promovendo a transmissão. Sob análise a contração [da], [de+a] (preposição de, artigo definido a) indica posse; a presença do artigo definido [a] indica que a informação possui traços culturais, fato que 
amplifica o contexto de aplicação. Neste ponto, está centrado na informação.

Por sua vez, também é possível reconhecer como o vocábulo [cultura de informação] ganha significados, sendo entendido como um processo que determina um tipo de cultura, especificando-a, trazendo a ideia de que se trata de um contexto que prega um recorte cultural mais específico, um domínio, ou seja, não se analisa comportamentos, tampouco as ações de seus actantes, pois [informação] restringe-se ao aspecto semântico de tipificação de uma cultura qualquer. A ausência do artigo definido [a] promove uma generalização de sentido.

A preposição [de] indica tipo, definição; o recorte de cultura aqui é específico, apenas se analisa o que é informativo e como essa propriedade caracteriza um tipo de cultura. Neste ponto está centrado na cultura. É preciso compreender que a palavra [CULTURA] possui muitos significados. Trata-se de um termo polissêmico, fator que se evidencia como um problema para a Ciência da Informação, já que há a necessidade de um denominador pontual para garantir um resgate mais efetivo, como um tesauro.

Analisando o termo [informacional], depreende-se um processo derivacional resgatando o vocábulo constituído no século XV enformacion, -çam, çõn, o qual sofre uma variação histórica, denominada metaplasmo por associação fonética: informacion, para posteriormente ser acrescido o sufixo [-al]. Também pode ser entendido que no processo de formação da palavra haja a sequência derivacional: [informar>informação>informacional], pelos mesmos motivos de adequação das derivações ocorridas no século XV (CUNHA, 1982).

Diante disso, percebe-se ao analisar o sufixo [-ação] que se trata de um sufixo nominativo (=cast. -ación; fr. -ation [> ing. -ation]; it.-azióne], deriv. do lat. -ātiō, -ōnis, que forma substantivos abstratos deverbais, com a noção básica de ação, ato. (CUNHA, 1986, p. 7). Nesse mesmo raciocínio, analisa-se o sufixo [-al], que se caracteriza por ser sufixo nominativo do latim -ālis, āle, que forma substantivos oriundos de outros substantivos, dando noção de conjunto, ainda adjetivos oriundos de substantivos, dando a noção de relação, pertinência (CUNHA, 1982).

Dessa forma, entende-se que os conceitos evocados pelos diversos especialistas que discutiram a configuração do termo são atendidos pelo termo [informacional], devido à sua natureza morfológica, que consiste em resgatar a ideia de ação: ato de informar, em que se pode identificar as prerrogativas sobre fluxo de informação e alfabetização informacional, somado às ideias de conjunto e relação, em que é possível perceber a ideia de organização das informações e organização do conhecimento, além da característica pertinente de pertencer a ciclo semiótico-semântico da Cultura Organizacional. 
Sendo assim, confrontando os diversos trabalhos de pesquisa, os debates acerca do termo e o suporte linguístico para compreender os traços semânticos dos termos envolvidos, entende-se que o termo preferido para representar deva ser cultura informacional, inclusive essa análise propõe suporte para a linguística documental a fim de consolidar este termo como um tesauro, assim garantindo que não haja mais ambiguidades e nem perda de informação no processo de indexação e recuperação da informação.

Dessa forma, entende-se também que o termo cultura informacional evoca o conceito em sua amplitude, assim como as linhas teóricas/temáticas abordadas por, Moraes e Barbosa (2015, p. 132), bem como a aplicação realizada por Woida (2016). Ainda é possível compreender que os demais termos que foram utilizados ao longo do tempo e citados ao longo deste trabalho como cultura da informação, alfabetização informacional se caracterizam por serem pertencentes àquilo que absorve a Cultura Informacional.

\section{Considerações finais}

Cultura informacional é um conceito amplo que tem se tornado importante para discutir linhas de atuações da Ciência da Informação, tendo em vista seu caráter inerente à Cultura Organizacional, assim como suas relações intrínsecas com outras áreas do conhecimento, não somente pelas questões que tangem a gestão da informação, bem como a organização desta e os procedimentos para a organização do conhecimento, mas também porque resgata conceitos e aplicações de outras áreas para debater a alfabetização informacional, os procedimentos metalinguísticos, assim como as metodologias pedagógicas.

Ao se pensar que essas ações ocorrem por natureza social, é preciso estreitar as relações da Cultura Informacional com o universo das organizações, bem como das Ciências Sociais. Ademais, em se tratando de fluxo de informação e as contribuições da tecnologia, é preciso manter as reflexões acerca das influências tecnológicas nas atribuições da cultura informacional.

Dessa forma, é válido destacar a Cultura Informacional como "o conhecimento sobre manejar a informação", somado "aos comportamentos e as atitudes em relação à informação, produtos e valores e crenças culturais do grupo" (PONJUÁN DANTE, 2007, apud WOIDA, 2016, p. 17), assim como Cultura Informacional também "corresponde a perspectivas ampliadas da organização e compreendem a cultura informacional como os comportamentos, as normas e os valores que são compartilhados, que dão significado e influenciam no uso da informação" (CHOO et al., 2008, apud WOIDA, 2016, p. 19) 
Portanto, entende-se que as três abordagens: de gestão, socioeducacional e tecnológico-comunicativo, como aponta Woida (2016) são fundamentais para entender a amplitude da temática, pois as abordagens dialogam e se reestruturam e não podem existir independentemente.

No que tange às aplicações do termo e do conceito, entende-se que o conceito apresentado pelos especialistas, ou o conjunto de predicativos atribuídos pelos diversos estudiosos sobre a temática caracteriza um campo de atuação e entendimento importante para o desenvolvimento de técnicas, teorias e procedimentos capazes de aperfeiçoar tanto o desenvolvimento do conhecimento nas organizações, como nos ambientes educacionais e sociais.

Já o termo, acredita-se que as teorias linguístico-morfológicas possam dirimir as dúvidas, mesmo porque muitos especialistas já entendem que [cultura informacional] representa melhor a entidade conceitual com que trabalham e desenvolvem seus projetos. No entanto, apenas a construção histórica discursiva poderá definir se esse termo será carregado de significados e simbologias para estabelecer uma tradição terminológica.

\section{Referências}

BARTHES, R. Elementos da Semiologia. Trad. Izidoro Blikstein. 16. ed. São Paulo: Cultrix, 2006.

BARTHES, R. Mitologias. Trad. Rita Buong. 4a ed. Rio de Janeiro: DIFEL, 2009.

BECHARA, E. Moderna gramática portuguesa. 37. ed. Rio de Janeiro: Lucerna, 2006.

CHOO, C. W. et al. Information culture and information use: an exploratory study of three organizations. Journal of the American for Information Science and Technology. v. 59, n. 5, 792-804, 2008.

CUNHA, A. G. Dicionário Etimológico Nova Fronteira da Língua Portuguesa. Assistentes Cláudio Mello Sobrinho et al. Rio de Janeiro: Nova Fronteira, 1982.

DAHLBERG, I. Teoria do Conceito. Ciência da Informação, 7(2), 101-107, 1978.

DUBOIS, J et al. Dicionário de Linguística. Trad. Bras. Izidoro Blikstein et al. São Paulo: Cultrix, 1998. 
HEGEL, G. W. F. Fenomenologia do espírito. 2. ed. Vozes: Rio de Janeiro, 1992.

HJORLAND, B. Concept Theory. Journal of the American Society for Information Science and Techonology, v. 60, n. 8, 1519-1536, 2009.

JAKOBSON, R. Linguística e Comunicação. Trad. Izidoro Blikstein. 26ed. São Paulo: Cultrix, 2011.

LE DEUFF, O. Bouillon de cultures la culture de l'information est-elle un concept international? Colloque ERTé 2008, L'éducation à la culture informationnelle, Oct 2008, France. pp.1-7, 2008. Disponível em: https://books.openedition.org/pressesenssib/833. Acesso em: 20 out. 2018.

MAURY, Y. Définition(s) de la culture informationnelle. [Rapport de recherche] Lille 3. 2010. Disponível em:

https://www.researchgate.net/publication/277329465 Definitions de la culture informationnelle. Acesso em: 05 nov. 2018.

MORAES, L. B.; BARBOSA, R. R. Cultura informacional: uma proposta de modelo com foco organizacional. Informação \& Sociedade, João Pessoa, v. 25, n. 3, p.131-146, dez. 2015. Disponível em: www.periodicos.ufpb.br. Acesso em: 02 nov. 2018.

PEIRCE, C. S. Semiótica. São Paulo: Perspectiva, 2000.

PICHS FERNÁNDEZ, A; PONJUÁN DANTE, G. La Cultura Informacional: sus principales relaciones conceptuales Ciencias de la Información, v. 45, n. 2, mayo-ago., 2014, pp. 33-37. Instituto de Información Científica y

Tecnológica La Habana, Cuba. Disponível em:

http://www.redalyc.org/articulo.oa?id=181432443006. Acesso em: 15 nov. 2018.

ROSA, M. C. Introdução à morfologia. 7. ed. São Paulo: Contexto, 2018.

SAUSSURE, F. Curso de linguística geral. Trad. Bras. Antônio Chelini et al. São Paulo: Cultrix, 2006.

SUNDQVIST, A.; SVÄRD, P. Information culture and records management: a suitable match? Conceptualizations of information culture and their application on records management. International Journal Of Information Management, [s.I.], v. 36, n. 1, p.9-15, fev. 2016. Elsevier BV. Disponível em:

https://www.sciencedirect.com/science/article/pii/S0268401215000870?vi a\%3Dihub. Acesso em: 05 nov. 2018. 
VIGOTSKI, L. S. A formação social da mente: o desenvolvimento dos processos psicológicos superiores. Trad. José Cipolla Neto; Luís Silveira Menna Barreto; Solange Castro Afeche. 7. ed. São Paulo: Martins Fontes, 2007.

WOIDA, L. M. A cultura informacional na Documentação. Jundiaí: Paco Editora, 2016.

ZABALA. A. A prática educativa: como ensinar. Trad. Ernani F. da Rosa. Porto Alegre: Artmed, 1998.

1 Por uma razão de precisão conceitual, optou-se em adotar sempre que a Cultura Informacional for tratada como campo de pesquisa, de estudo ou disciplina acadêmica, será grafada em maiúscula. Paralelamente, quando figurar em minúsculo, a acepção tomada será como fenômeno ou objeto de estudo. Portanto, para facilitar a distinção entre campo e objeto, o texto trará Cultura Informacional quando se referir a campo e cultura informacional quando o caso diz respeito a um objeto. Também serão utilizados colchetes [ ] para indicar que o termo inserido será tratado como vocábulo e a ele promovida uma análise metalinguística.

2 Como apontam os especialistas, processo contínuo que envolve normas, valores, ritua is, crenças, elementos simbólicos e procedimentos comunicativos na estruturação de fluxo informacional, assim como estratégias de gerenciamento a fim de compor um cenário frutífero de inteligência competitiva para estabelecer objetivos, assim como potencializar as ações de uma empresa ou organização. Devido a importância da informação nesse ciclo, bem como os vetores agentes da cultura, pode-se compreender a relação intrínseca de valores teóricos entre a Cultura Informacional e a Cultura Organizacional para esta área da Ciência da Informação. 